\title{
Viscosity Method for Hierarchical Fixed Point Problems with an Infinite Family of Nonexpansive Nonself-Mappings
}

\author{
Yaqin Wang ${ }^{1,2}$ \\ ${ }^{1}$ Department of Mathematics, Shaoxing University, Shaoxing 312000, China \\ ${ }^{2}$ Mathematical College, Sichuan University, Chengdu, Sichuan 610064, China \\ Correspondence should be addressed to Yaqin Wang; wangyaqin0579@126.com
}

Received 4 January 2013; Accepted 22 March 2013

Academic Editor: Filomena Cianciaruso

Copyright (c) 2013 Yaqin Wang. This is an open access article distributed under the Creative Commons Attribution License, which permits unrestricted use, distribution, and reproduction in any medium, provided the original work is properly cited.

A viscosity method for hierarchical fixed point problems is presented to solve variational inequalities, where the involved mappings are nonexpansive nonself-mappings. Solutions are sought in the set of the common fixed points of an infinite family of nonexpansive nonself-mappings. The results generalize and improve the recent results announced by many other authors.

\section{Introduction and Preliminaries}

Let $X$ a real Banach space and $J$ be the normalized duality mapping from $X$ into $2^{X^{*}}$ given by

$$
J(x)=\left\{x^{*} \in X^{*}:\left\langle x, x^{*}\right\rangle=\|x\|\left\|x^{*}\right\|,\|x\|=\left\|x^{*}\right\|\right\}
$$

for all $x \in X$, where $X^{*}$ denotes the dual space of $X$ and $\langle\cdot, \cdot\rangle$ the generalized duality pairing between $X$ and $X^{*}$. If $X=H$ is a Hilbert space, then $J$ becomes the identity mapping on $H$. A point $x \in C$ is a fixed point of $T: C \subset X \rightarrow X$ provided $T x=x$. Denote by $F(T)$ the set of fixed points of $T$; that is, $F(T)=\{x \in C: T x=x\}$.

Let $X$ be a normed linear space with $\operatorname{dim} X \geq 2$. The modulus of smoothness of $X$ is the function $\rho_{X}:[0,+\infty) \rightarrow$ $[0,+\infty)$ defined by

$$
\rho_{X}(\tau):=\sup \left\{\frac{\|x+y\|+\|x-y\|}{2}-1:\|x\|=1,\|y\|=\tau\right\} .
$$

The space $X$ is said to be smooth if $\rho_{X}(\tau)>0$, for all $\tau>0$. It is well known that if $X$ is smooth then $J$ is single valued. A Banach space $X$ is said to be strictly convex if $\|x\|=\|y\|=$ $1, x \neq y$, implies $\|x+y\| / 2<1$.

Let $C$ be a nonempty closed convex subset of a real Banach space $X$. Recall the following concepts.
Definition 1. (i) A mapping $f: C \rightarrow C$ is a $\rho$-contraction if $\rho \in[0,1)$ and if the following property is satisfied

$$
\|f(x)-f(y)\| \leq \rho\|x-y\|, \quad \forall x, y \in C .
$$

(ii) A mapping $T: C \rightarrow E$ is nonexpansive provided

$$
\|T x-T y\| \leq\|x-y\|, \quad \forall x, y \in C .
$$

(iii) A mapping $S: C \rightarrow X$ is

(a) accretive if for any $x, y \in C$ there exists $j(x-y) \in$ $J(x-y)$ such that

$$
\langle S x-S y, j(x-y)\rangle \geq 0
$$

(b) $\beta$-strongly accretive if for any $x, y \in C$ there exists $j(x-y) \in J(x-y)$ such that

$$
\langle S x-S y, j(x-y)\rangle \geq \beta\|x-y\|^{2},
$$

for some real constant $\beta>0$.

Noting that if $S: C \rightarrow X$ is nonexpansive, then $I-S$ is accretive; if $f: C \rightarrow C$ is a $\rho$-contraction, then $I-f$ is $(1-\rho)$-strongly accretive. particulary, if $X=H$ is a Hilbert space, then (strongly) accretive mappings become (strongly) monotone mappings. 
Definition 2. Let $C$ and $D$ be nonempty subsets of a Banach space $X$ such that $C$ is nonempty closed convex and $D \subset C$.

(i) A mapping $Q: C \rightarrow D$ is called sunny, if $Q(Q x+$ $t(x-Q x))=Q x$ for each $x \in C$ and $t \geq 0$ with $Q(Q x+t(x-Q x)) \in C$.

(ii) A mapping $Q: C \rightarrow D$ is called a retraction from $C$ to $D$ if $Q$ is continuous and $F(Q)=D$.

(iii) A subset $D$ of $C \subset E$ is said to be a sunny nonexpansive retract of $C$ if there exists a sunny nonexpansive retraction $Q$ of $C$ onto $D$. For details, see $[1-3]$.

Note that if $X=H$ is a Hilbert space, $Q$ becomes the projection on $C$, denoted by $P_{C}$.

Let $P: C \rightarrow C$ a nonexpansive self-mapping on $C$ and $\left\{T_{n}\right\}$ be a countable family of nonexpansive nonselfmappings of $C$ into $X$ such that $\mathscr{F}=\bigcap_{n=1}^{\infty} F\left(T_{n}\right) \neq \emptyset$. Then we consider the following problem: find hierarchically a common fixed point of the infinite family $\left\{T_{n}\right\}$ with respect to a nonexpansive mapping $P$; namely, find $x^{*} \in \mathscr{F}$, such that

$$
\left\langle x^{*}-P x^{*}, J\left(x-x^{*}\right)\right\rangle \geq 0, \quad \forall x \in \mathscr{F} .
$$

Particularly, if $\left\{T_{n}\right\}$ is a finite family of nonexpansive nonself-mappings, problem (7) has been studied by Ceng and Petruşel [4]. If $X=H$ and $\left\{T_{n}\right\}$ is an infinite family of nonexpansive self-mappings, Problem (7) reduces to the following problem: find hierarchically a common fixed point of $\left\{T_{n}\right\}$ with respect to a nonexpansive mapping $P$, namely, find $x^{*} \in \mathscr{F}$, such that

$$
\left\langle x^{*}-P x^{*}, x-x^{*}\right\rangle \geq 0, \quad \forall x \in \mathscr{F},
$$

which was studied by Zhang et al. [5]. If $X=H$ is a Hilbert space and $T_{n}=T$, for all $n \geq 1$, where $T$ is a nonexpansive mapping on $C$, then problem (7) reduces to the following problem: finding hierarchically a fixed point of $T$ with respect to another nonexpansive mapping $P$; namely, find $x^{*} \in F(T)$ such that

$$
\left\langle x^{*}-P x^{*}, x-x^{*}\right\rangle \geq 0, \quad \forall x \in F(T) .
$$

Problem (7) includes many problems as special cases, so it is very important in the area of optimization and related fields, such as signal processing and image reconstruction (see [6-9]).

In 2007, Moudafi [10] introduced the following Krasnoselski-Mann's algorithm in Hilbert spaces:

$$
\begin{array}{r}
x_{n+1}=\left(1-\alpha_{n}\right) x_{n}+\alpha_{n}\left(\sigma_{n} P x_{n}+\left(1-\sigma_{n}\right) T x_{n}\right), \\
\forall n \geq 0,
\end{array}
$$

where $\left\{\alpha_{n}\right\}$ and $\left\{\sigma_{n}\right\}$ are two real sequences in $(0,1)$ and $T$ and $P$ are two nonexpansive mappings of $C$ into itself. Furthermore, he established a weak convergence result for Algorithm (10) for solving problem (9).

Subsequently, Yao and Liou [11] derived a weak convergence result of algorithm (10) under the restrictions on parameters weaker than those in [10, Theorem 2.1].
Recently, Marino and $\mathrm{Xu}$ [12] introduced the following explicit hierarchical fixed point algorithm in Hilbert spaces:

$$
\begin{array}{r}
x_{n+1}=\lambda_{n} f\left(x_{n}\right)+\left(1-\lambda_{n}\right)\left(\alpha_{n} V x_{n}+\left(1-\alpha_{n}\right) T x_{n}\right), \\
\forall n \geq 0,
\end{array}
$$

where $f$ is a contraction on $C$ and $V, T$ are two nonexpansive mappings of $C$ into itself and proved that the sequence $\left\{x_{n}\right\}$ generated by (11) converges strongly to a solution of problem (9).

Very recently, Zhang et al. [5] introduced the following iterative algorithm in order to find hierarchically a fixed point of Problem (8):

$$
\begin{gathered}
x_{0} \in C, \\
x_{n+1}=\alpha_{n} f\left(x_{n}\right)+\left(1-\alpha_{n}\right) y_{n}, \\
y_{n}=\beta_{n} P\left(x_{n}\right)+\left(1-\beta_{n}\right) T x_{n},
\end{gathered}
$$

where $f: C \rightarrow C$ is a contraction, $P: C \rightarrow C$ is a nonexpansive mapping, $\left\{T_{n}\right\}: C \rightarrow C$ is a countable family of nonexpansive mappings, and $T: C \rightarrow C$ is a mapping defined by

$$
T=\sum_{n=1}^{\infty} \lambda_{n} T_{n}, \quad \lambda_{n} \geq 0 \quad(n=1,2, \ldots) \text { with } \sum_{n=1}^{\infty} \lambda_{n}=1 .
$$

Under suitable conditions on parameters $\left\{\alpha_{n}\right\}$ and $\left\{\beta_{n}\right\}$, they established some strong and weak convergence theorems. Note that, in [5], $\left\{T_{n}\right\}$ is an infinite family of self-mappings and $P$ is also a self-mapping. And they obtained the results in the setting of Hilbert spaces.

Motivated and inspired by the above researches, in a reflexive Banach space which admits a weakly sequentially continuous duality mapping $J$, we propose and analyze an iteration process for a countable family of nonexpansive nonself-mappings $\left\{T_{n}\right\}: C \rightarrow X$ and $S: C \rightarrow X$ is a nonexpansive nonself-mapping as follows:

$$
\begin{gathered}
x_{0} \in C, \\
x_{n+1}=Q\left(\alpha_{n} f\left(x_{n}\right)+\left(1-\alpha_{n}\right) y_{n}\right), \\
y_{n}=\beta_{n} S x_{n}+\left(1-\beta_{n}\right) T x_{n}, \quad n \geq 0,
\end{gathered}
$$

where $Q$ is a sunny nonexpansive retraction of $X$ onto $C$ and establishes a convergence theorem. particularly, if $X=H$ is a Hilbert space, we obtain some convergence results.

To prove the main results, we need the following lemmas.

Lemma 3 (see [1]). Let $C$ be a nonempty and convex subset of a smooth Banach space $X, D \subset C, J: X \rightarrow X^{*}$ the normalized duality mapping of $X$, and $Q: C \rightarrow D$ a retraction. Then the following conditions are equivalent:

(i) $\langle x-Q x, J(y-Q x)\rangle \leq 0$, for all $x \in C$ and $y \in D$;

(ii) $Q$ is both sunny and nonexpansive.

Lemma 4 (see $[13$, Lemma 3.1,3.3]). Let $X$ be a real smooth and strictly convex Banach space and $C$ a nonempty closed and 
convex subset of $X$ which is also a sunny nonexpansive retract of $X$. Assuming that $T: C \rightarrow X$ is a nonexpansive mapping and $Q$ is a sunny nonexpansive retraction of $X$ onto $C$, then $F(T)=F(Q T)$.

Lemma 5 (see [1]). Let $X$ be a real Banach space and $J: X \rightarrow$ $2^{X^{*}}$ the normalized duality mapping. Then for any $x, y \in X$, the following hold:

(i) $\|x+y\|^{2} \leq\|x\|^{2}+2\langle y, j(x+y)\rangle$, for all $j(x+y) \epsilon$ $J(x+y)$

(ii) $\|x\|^{2}+2\langle y, j(x)\rangle \leq\|x+y\|^{2}$, for all $j(x) \in J(x)$.

Lemma 6 (see [14]). Let $\left\{a_{n}\right\}$ and $\left\{b_{n}\right\}$ be two sequences of nonnegative real numbers satisfying

$$
\begin{gathered}
\sum_{n=0}^{\infty} b_{n}<\infty \\
a_{n+1} \leq a_{n}+b_{n}, \quad n=0,1,2, \ldots
\end{gathered}
$$

Then $\lim _{n \rightarrow \infty} a_{n}$ exists.

Lemma 7 (see [15]). Let $\left\{a_{n}\right\}$ be a sequence of nonnegative real numbers satisfying

$$
a_{n+1} \leq\left(1-\lambda_{n}\right) a_{n}+\lambda_{n} b_{n}+c_{n}, \quad \forall n \geq 0,
$$

where $\left\{\lambda_{n}\right\},\left\{b_{n}\right\}$ and $\left\{c_{n}\right\}$ satisfy the following conditions:

(i) $\left\{\lambda_{n}\right\} \subset[0,1], \sum_{n=0}^{\infty} \lambda_{n}=\infty$ or, equivalently, $\Pi_{n=0}^{\infty}(1-$ $\left.\lambda_{n}\right)=0$;

(ii) $\lim \sup _{n \rightarrow \infty} b_{n} \leq 0$;

(iii) $c_{n} \geq 0(n \geq 0), \quad \sum_{n=0}^{\infty} c_{n}<\infty$.

Then $\lim _{n \rightarrow \infty} a_{n}=0$.

If Banach space $X$ admits sequentially continuous duality mapping $J$ from weak topology to weak $*$ topology, then by $[16$, Lemma 1] we get that duality mapping $J$ is singlevalued. In this case, duality mapping $J$ is also said to be weakly sequentially continuous, that is, for each $\left\{x_{n}\right\} \subset X$ with $x_{n} \rightarrow$ $x$, then $J\left(x_{n}\right) \rightarrow J x[16,17]$.

Recall that a Banach space $X$ is said to be satisfying Opial's condition if for any sequence $\left\{x_{n}\right\}$ in $E, x_{n} \rightarrow x(n \rightarrow \infty)$ implies that

$$
\limsup _{n \rightarrow \infty}\left\|x_{n}-x\right\|<\limsup _{n \rightarrow \infty}\left\|x_{n}-y\right\|, \quad \forall y \in E \text {, with } y \neq x .
$$

By [16, Lemma 1], we know that if $X$ admits a weakly sequentially continuous duality mapping, then $X$ satisfies Opial's condition.

In the sequel, we also need the following lemmas.

Lemma 8 (see [17]). Let $C$ be a nonempty, closed and convex subset of a reflexive Banach space $X$ which satisfies Opial's condition and $T: C \rightarrow X$ a nonexpansive mapping. Then the mapping $I-T$ is demiclosed at zero, that is,

$$
\begin{aligned}
& x_{n} \rightarrow x \\
& x_{n}-T x_{n} \longrightarrow 0 \\
& \quad \text { imply } x=T x .
\end{aligned}
$$

Let $C$ be a nonempty and convex subset of a Banach space $X$. Then for $x \in C$, one defines the inward set $I_{C}(x)$ as follows $[2,3]$ :

$$
I_{C}(x)=\{y \in X: y=x+\lambda(z-x), z \in C, \lambda \geq 0\} .
$$

A mapping $T: C \rightarrow X$ is said to satisfy the inward condition if Tx $\in I_{C}(x)$ for all $x \in C$. T is also said to satisfy the weakly inward condition if for each $x \in C, T x \in \overline{I_{C}(x)}\left(\overline{I_{C}(x)}\right.$ is the closure of $\left.I_{C}(x)\right)$. Clearly $C \subset I_{C}(x)$ and it is not hard to show that $I_{C}(x)$ is a convex set if $C$ does.

Lemma 9 (see [18, Theorem 2.4]). Let $X$ be a reflexive Banach space which admits a weakly sequentially continuous duality mapping $J$ from $X$ to $X^{*}$. Suppose $C$ is a nonempty closed convex subset of $X$ which is also a sunny nonexpansive retract of $X$, and $T: C \rightarrow X$ is a nonexpansive mapping satisfying the weakly inward condition and $F(T) \neq \emptyset$. Let $\left\{u_{n}\right\}$ be defined by

$$
\begin{gathered}
u_{0} \in C, \\
u_{n+1}=Q\left(\alpha_{n} f\left(u_{n}\right)+\left(1-\alpha_{n}\right) T u_{n}\right),
\end{gathered}
$$

where $Q$ is a sunny nonexpansive retract of $X$ onto $C$ and $\alpha_{n} \epsilon$ $(0,1)$ satisfy the following conditions:

(i) $\alpha_{n} \rightarrow 0$, as $n \rightarrow \infty$;

(ii) $\sum_{n=0}^{\infty} \alpha_{n}=\infty$;

(iii) either $\sum_{n=0}^{\infty}\left|\alpha_{n+1}-\alpha_{n}\right|<\infty$ or $\lim _{n \rightarrow \infty}\left(\alpha_{n} / \alpha_{n+1}\right)=1$.

Then $\left\{x_{n}\right\}$ converges strongly to a fixed point $p$ of $T$ such that $p$ is the unique solution in $F(T)$ to the following variational inequality:

$$
\langle(I-f) p, j(p-u)\rangle \leq 0, \quad \forall u \in F(T) .
$$

Remark 10. If a Banach space $X$ admits a sequentially continuous duality mapping $J$ from weak topology to weak star topology, from Lemma 1 of [16] it follows that $X$ is smooth. So for Lemma 9, if $X$ is a reflexive and strictly convex Banach space which admits a weakly sequentially continuous duality mapping $J$, by Lemma 4, the weakly inward condition of $T$ can be removed.

\section{Main Results}

Theorem 11. Let $X$ be a reflexive and strictly convex Banach space which admits a weakly sequentially continuous duality mapping $J: X \rightarrow X^{*}$ and $C$ a nonempty, closed and convex subset of $X$ which is also a sunny nonexpansive retract of $X$. Let $S: C \rightarrow X$ be a nonexpansive nonself-mapping, $f: C \rightarrow C$ 
a contractive mapping with a contractive constant $\rho \in(0,1)$ and $T_{i}: C \rightarrow X(i=\{1,2, \ldots\})$ an infinite family of nonexpansive nonself-mappings such that $\bigcap_{i=1}^{\infty} F\left(T_{i}\right) \neq \emptyset$. Let $T: C \rightarrow X$ be defined by (13) and $Q$ a sunny nonexpansive retraction of $X$ onto $C$. Let $\left\{x_{n}\right\}$ be the sequence generated by $(14)$, and $\left\{\alpha_{n}\right\}$ and $\left\{\beta_{n}\right\}$ the sequences in $(0,1)$ satisfying the following conditions:

(i) $\alpha_{n} \rightarrow 0(n \rightarrow \infty), \sum_{n=0}^{\infty} \alpha_{n}=\infty$;

(ii) $\lim _{n \rightarrow \infty}\left(\beta_{n} / \alpha_{n}\right)=0$;

(iii) $\sum_{n=0}^{\infty}\left|\alpha_{n+1}-\alpha_{n}\right|<\infty$.

Then $\left\{x_{n}\right\}$ converges strongly to some point $x^{*} \in F(T)=$ $\bigcap_{i=1}^{\infty} F\left(T_{i}\right)$, which is the unique solution to the following variational inequality:

$$
\left\langle(I-f) x^{*}, J\left(x-x^{*}\right)\right\rangle \geq 0, \quad \forall x \in F(T) .
$$

Proof. From condition (ii), without loss of generality, we can assume that $\beta_{n} \leq \alpha_{n}$, for all $n \geq 0$.

First we prove that the sequence $\left\{x_{n}\right\}$ is bounded.

In fact, for any $u \in F(T)$, we have

$$
\begin{aligned}
\left\|x_{n+1}-u\right\| & \\
= & \left\|Q\left(\alpha_{n} f\left(x_{n}\right)+\left(1-\alpha_{n}\right) y_{n}\right)-Q u\right\| \\
\leq & \alpha_{n}\left\|f\left(x_{n}\right)-u\right\|+\left(1-\alpha_{n}\right)\left\|\beta_{n} S x_{n}+\left(1-\beta_{n}\right) T x_{n}-u\right\| \\
\leq & \alpha_{n}\left(\rho\left\|x_{n}-u\right\|+\|f(u)-u\|\right) \\
& +\left(1-\alpha_{n}\right)\left(\beta_{n}\left\|S x_{n}-u\right\|+\left(1-\beta_{n}\right)\left\|T x_{n}-u\right\|\right) \\
\leq & \left(1-\alpha_{n}(1-\rho)\right)\left\|x_{n}-u\right\|+\alpha_{n}\|f(u)-u\| \\
& +\left(1-\alpha_{n}\right) \beta_{n}\|S u-u\| \\
\leq & \left(1-\alpha_{n}(1-\rho)\right)\left\|x_{n}-u\right\| \\
& +\alpha_{n}(\|f(u)-u\|+\|S u-u\|) \\
\leq & \max \left\{\left\|x_{n}-u\right\|, \frac{\|f(u)-u\|+\|S u-u\|}{1-\rho}\right\} .
\end{aligned}
$$

By induction,

$$
\left\|x_{n+1}-u\right\| \leq \max \left\{\left\|x_{0}-u\right\|, \frac{\|f(u)-u\|+\|S u-u\|}{1-\rho}\right\} .
$$

Thus $\left\{x_{n}\right\}$ is bounded, so $\left\{S x_{n}\right\}$ and $\left\{T x_{n}\right\}$ are also bounded.

Next we prove that $\left\|x_{n}-u_{n}\right\| \rightarrow 0$, as $n \rightarrow \infty$, where the sequence $\left\{u_{n}\right\}$ is defined by

$$
\begin{gathered}
u_{0}=x_{0} \in C, \\
u_{n+1}=Q\left(\alpha_{n} f\left(u_{n}\right)+\left(1-\alpha_{n}\right) T u_{n}\right) .
\end{gathered}
$$

By Lemma 9 and Remark 10, $\left\{u_{n}\right\}$ converges strongly to some point $x^{*} \in F(T)$, which is the unique solution to the following variational inequality:

$$
\left\langle(I-f) x^{*}, j\left(x^{*}-x\right)\right\rangle \leq 0, \quad \forall x \in F(T) .
$$

Furthermore, we obtain

$$
\begin{aligned}
\left\|x_{n+1}-u_{n+1}\right\| & \\
\leq & \| Q\left(\alpha_{n} f\left(x_{n}\right)+\left(1-\alpha_{n}\right) y_{n}\right) \\
& \quad-Q\left(\alpha_{n} f\left(u_{n}\right)+\left(1-\alpha_{n}\right) T u_{n}\right) \| \\
\leq & \left\|\alpha_{n}\left(f\left(x_{n}\right)-f\left(u_{n}\right)\right)+\left(1-\alpha_{n}\right)\left(y_{n}-T u_{n}\right)\right\| \\
\leq & \alpha_{n} \rho\left\|x_{n}-u_{n}\right\|+\left(1-\alpha_{n}\right) \\
& \times\left(\beta_{n}\left\|S x_{n}-T u_{n}\right\|+\left(1-\beta_{n}\right)\left\|T x_{n}-T u_{n}\right\|\right) \\
\leq & \left(1-\alpha_{n}(1-\rho)\right)\left\|x_{n}-u_{n}\right\|+\left(1-\alpha_{n}\right) \beta_{n} M \\
\leq & \left(1-\alpha_{n}(1-\rho)\right)\left\|x_{n}-u_{n}\right\|+\beta_{n} M,
\end{aligned}
$$

where $M=\sup _{n \geq 0}\left\|S x_{n}-T u_{n}\right\|$. It follows from conditions (i)(ii) and Lemma 7 we have $\lim _{n \rightarrow \infty}\left\|x_{n}-u_{n}\right\|=0$. Since as $n \rightarrow$ $\infty, u_{n} \rightarrow x^{*} \in F(T)$, we get $x_{n} \rightarrow x^{*}(n \rightarrow \infty)$, which is the unique solution to the variational inequality (22).

Remark 12. Theorem 11 extends Theorem 2.1 in [5] from the following aspects: (i) from Hilbert spaces to reflexive and strictly convex Banach spaces which admits a weakly sequentially continuous duality mapping; (ii) for the infinite family of mappings $\left\{T_{i}\right\}$ from self-mappings to nonself-mappings. In addition, the existence of the sunny nonexpansive retraction has been proved in [19, Theorem 3.10].

Remark 13. If we take

$$
\begin{aligned}
& \alpha_{n}=\frac{1}{(1+n)^{\alpha},} \\
& \beta_{n}=\frac{1}{(1+n)^{\beta}}, \\
& 0<\alpha<\beta<1,
\end{aligned}
$$

then since $\left|\alpha_{n+1}-\alpha_{n}\right| \approx 1 / n^{\alpha+1}$ and $\left|\beta_{n+1}-\beta_{n}\right| \approx 1 / n^{\beta+1}$ (as $n \rightarrow \infty$ ), it is not hard to find that the conditions (i)-(iii) are satisfied. For details, see [12, Remark 3.2].

In the sequel, we consider the result in the setting of Hilbert spaces.

Theorem 14. Let $H$ be a Hilbert space and $C$ a nonempty, closed and convex subset of $H$. Let $S: C \rightarrow H$ be $a$ nonexpansive nonself-mapping, $f: C \rightarrow C$ a contractive mapping with a contractive constant $\rho \in(0,1)$, and $T_{i}: C \rightarrow$ $H(i=\{1,2, \ldots\})$ an infinite family of nonexpansive nonselfmappings such that $F(T)=\bigcap_{i=1}^{\infty} F\left(T_{i}\right) \neq \emptyset$. Let $\left\{x_{n}\right\}$ be the sequence generated by (14) and $\left\{\alpha_{n}\right\}$ and $\left\{\beta_{n}\right\}$ the sequences in $(0,1)$ satisfying the following conditions:

(i) $\alpha_{n} \rightarrow 0, \sum_{n=0}^{\infty} \alpha_{n}=\infty$;

(ii) $\lim _{n \rightarrow \infty}\left(\beta_{n} / \alpha_{n}\right)=\tau \in(0,+\infty)$;

(iii) $\lim _{n \rightarrow \infty}\left(\left(\left|\beta_{n}-\beta_{n-1}\right|+\left|\alpha_{n}-\alpha_{n-1}\right|\right) / \alpha_{n} \beta_{n}\right)=0$;

(iv) there exists a constant $K>0$ such that $1 / \alpha_{n} \mid\left(1 / \beta_{n}\right)-$ $\left(1 / \beta_{n-1}\right) \mid \leq K$ for all $n>0$. 
Then $\left\{x_{n}\right\}$ converges strongly to some point $x^{*} \in F(T)$, which is the unique solution to the following variational inequality:

$$
\left\langle\frac{1}{\tau}(I-f) x^{*}+(I-S) x^{*}, x-x^{*}\right\rangle \geq 0, \quad \forall x \in F(T) .
$$

Proof. By condition (ii), without loss of generality, we can assume that $\beta_{n} \leq(\tau+1) \alpha_{n}$, for all $n \geq 0$. Similar to the proof of (24), for any $u \in F(T)$, we have

$$
\begin{aligned}
& \left\|x_{n+1}-u\right\| \\
& \quad \leq \max \left\{\left\|x_{0}-u\right\|, \frac{(\tau+1)(\|f(u)-u\|+\|S u-u\|)}{1-\rho}\right\} .
\end{aligned}
$$

Thus $\left\{x_{n}\right\}$ is bounded. Furthermore, $\left\{f\left(x_{n}\right)\right\},\left\{T x_{n}\right\},\left\{y_{n}\right\}$, $\left\{S x_{n}\right\}$ are all bounded. Put $u_{n}=\alpha_{n} f\left(x_{n}\right)+\left(1-\alpha_{n}\right) y_{n}$ and $M=\sup _{n \geq 0}\left\{\left\|f\left(x_{n}\right)\right\|+\left\|y_{n}\right\|,\left\|T x_{n}\right\|+\left\|S x_{n}\right\|\right\}$. So $\left\{u_{n}\right\}$ and $\left\{P_{C}\left(u_{n}\right)\right\}$ are also bounded.

Step 1 . We prove that $\left\|x_{n+1}-x_{n}\right\| \rightarrow 0(n \rightarrow \infty)$.

From (14), we obtain

$$
\begin{aligned}
\left\|x_{n+1}-x_{n}\right\| & \\
= & \left\|P_{C}\left(u_{n}\right)-P_{C}\left(u_{n-1}\right)\right\| \leq\left\|u_{n}-u_{n-1}\right\| \\
\leq & \alpha_{n}\left\|f\left(x_{n}\right)-f\left(x_{n-1}\right)\right\|+\left(1-\alpha_{n}\right)\left\|y_{n}-y_{n-1}\right\| \\
& +\left|\alpha_{n}-\alpha_{n-1}\right|\left(\left\|f\left(x_{n-1}\right)\right\|+\left\|y_{n-1}\right\|\right) \\
\leq & \alpha_{n} \rho\left\|x_{n}-x_{n-1}\right\|+\left(1-\alpha_{n}\right) \\
& \times\left\|y_{n}-y_{n-1}\right\|+\left|\alpha_{n}-\alpha_{n-1}\right| M, \\
\| y_{n} & -y_{n-1} \| \\
\leq & \beta_{n}\left\|S x_{n}-S x_{n-1}\right\|+\left(1-\beta_{n}\right)\left\|T x_{n}-T x_{n-1}\right\| \\
& +\left|\beta_{n}-\beta_{n-1}\right|\left(\left\|S x_{n-1}\right\|+\left\|T x_{n-1}\right\|\right) \\
\leq & \left\|x_{n}-x_{n-1}\right\|+\left|\beta_{n}-\beta_{n-1}\right| M .
\end{aligned}
$$

Substituting (32) into (31), we have

$$
\begin{aligned}
\left\|x_{n+1}-x_{n}\right\| \leq & \left(1-\alpha_{n}(1-\rho)\right)\left\|x_{n}-x_{n-1}\right\| \\
& +\alpha_{n} \frac{\left(\left|\alpha_{n}-\alpha_{n-1}\right|+\left|\beta_{n}-\beta_{n-1}\right|\right) M}{\alpha_{n}} .
\end{aligned}
$$

By conditions (i), (iii), and Lemma 7 , we have $\left\|x_{n+1}-x_{n}\right\| \rightarrow$ $0(n \rightarrow \infty)$.

Step 2. We prove that $\omega_{w}\left(x_{n}\right) \subset F(T)$, where $\omega_{w}\left(x_{n}\right)$ is the $\omega$-limit point set of $\left\{x_{n}\right\}$ in the weak topology:

$$
\begin{aligned}
& \left\|x_{n+1}-Q T x_{n}\right\| \\
& \quad \leq \alpha_{n}\left\|f\left(x_{n}\right)\right\|+\beta_{n}\left\|S x_{n}\right\|+\left(\alpha_{n}+\beta_{n}+\alpha_{n} \beta_{n}\right)\left\|T x_{n}\right\| .
\end{aligned}
$$

Noting that $\alpha_{n} \rightarrow 0$ and $\beta_{n} \rightarrow 0$, we have $\left\|x_{n+1}-Q T x_{n}\right\| \rightarrow$ $0(n \rightarrow \infty)$. Then from Step 1 we have $\left\|x_{n}-Q T x_{n}\right\| \rightarrow$ $0(n \rightarrow \infty)$. Furthermore, it follows from Lemmas 4 and 8 that $\omega_{w}\left(x_{n}\right) \subset F(Q T)=F(T)$, where $Q=P_{C}$.

Step 3. We show that $\left\|x_{n+1}-x_{n}\right\| / \beta_{n} \rightarrow 0(n \rightarrow \infty)$. It follows from (31) and (33) that

$$
\begin{aligned}
& \frac{\left\|x_{n+1}-x_{n}\right\|}{\beta_{n}} \\
& \leq \frac{\left\|u_{n}-u_{n-1}\right\|}{\beta_{n}} \leq\left(1-\alpha_{n}(1-\rho)\right) \frac{\left\|x_{n}-x_{n-1}\right\|}{\beta_{n-1}} \\
& +\left(1-\alpha_{n}(1-\rho)\right)\left\|x_{n}-x_{n-1}\right\|\left|\frac{1}{\beta_{n}}-\frac{1}{\beta_{n-1}}\right| \\
& +\frac{\left(\left|\alpha_{n}-\alpha_{n-1}\right|+\left|\beta_{n}-\beta_{n-1}\right|\right) M}{\beta_{n}} \\
& \leq+\left(1-\alpha_{n}(1-\rho)\right) \frac{\left\|x_{n}-x_{n-1}\right\|}{\beta_{n-1}} \\
& +\alpha_{n}\left\|x_{n}-x_{n-1}\right\| K \\
& +\frac{\left(\left|\alpha_{n}-\alpha_{n-1}\right|+\left|\beta_{n}-\beta_{n-1}\right|\right) M}{\alpha_{n} \beta_{n}} \alpha_{n} .
\end{aligned}
$$

By conditions (i) and (iii), $\left\|x_{n}-x_{n-1}\right\| \rightarrow 0(n \rightarrow \infty)$, and Lemma 7, we have

$$
\frac{\left\|x_{n+1}-x_{n}\right\|}{\beta_{n}} \longrightarrow 0 \quad(n \longrightarrow \infty) \text {. }
$$

Thus from (35), we get

$$
\frac{\left\|u_{n}-u_{n-1}\right\|}{\beta_{n}} \longrightarrow 0 \quad(n \longrightarrow \infty)
$$

Step 4. We show that $\left\{x_{n}\right\}$ converges strongly to some point $x^{\prime} \in F(T)$, which is the unique solution of (29).

Setting $W_{n}=\beta_{n} S+\left(1-\beta_{n}\right) T$, we have

$$
x_{n+1}=P_{C}\left(u_{n}\right)-u_{n}+\alpha_{n} f\left(x_{n}\right)+\left(1-\alpha_{n}\right) W_{n} x_{n} .
$$

Then

$$
\begin{aligned}
& x_{n}-x_{n+1} \\
& \quad=u_{n}-P_{C}\left(u_{n}\right)+\alpha_{n}(I-f) x_{n}+\left(1-\alpha_{n}\right)\left(I-W_{n}\right) x_{n} .
\end{aligned}
$$

Letting $v_{n}=\left(x_{n}-x_{n+1}\right) /\left(1-\alpha_{n}\right) \beta_{n}$, from condition (i) and (36), we have $v_{n} \rightarrow 0(n \rightarrow \infty)$. Noting that $I-W_{n}$ is 
monotone and $I-f$ is $(1-\rho)$-strongly monotone, for any $x^{*} \in F(T)$, from Lemma 3 we obtain

$$
\begin{aligned}
& \left\langle v_{n}, x_{n}-x^{*}\right\rangle \\
& =\frac{1}{\left(1-\alpha_{n}\right) \beta_{n}}\left\langle u_{n}-P_{C}\left(u_{n}\right), x_{n}-x^{*}\right\rangle \\
& +\frac{\alpha_{n}}{\left(1-\alpha_{n}\right) \beta_{n}}\left\langle(I-f) x_{n}, x_{n}-x^{*}\right\rangle \\
& +\frac{1}{\beta_{n}}\left\langle\left(I-W_{n}\right) x_{n}, x_{n}-x^{*}\right\rangle \\
& =\frac{1}{\left(1-\alpha_{n}\right) \beta_{n}}\left\langle u_{n}-P_{C}\left(u_{n}\right), x_{n}-x^{*}\right\rangle \\
& +\frac{\alpha_{n}}{\left(1-\alpha_{n}\right) \beta_{n}}\left\langle(I-f) x_{n}, x_{n}-x^{*}\right\rangle \\
& +\frac{1}{\beta_{n}}\left\langle\left(I-W_{n}\right) x_{n}-\left(I-W_{n}\right) x^{*}, x_{n}-x^{*}\right\rangle \\
& +\frac{1}{\beta_{n}}\left\langle\left(I-W_{n}\right) x^{*}, x_{n}-x^{*}\right\rangle \\
& =\frac{1}{\left(1-\alpha_{n}\right) \beta_{n}}\left\langle u_{n}-P_{C}\left(u_{n}\right), P_{C}\left(u_{n}\right)-x^{*}\right\rangle \\
& +\frac{1}{\left(1-\alpha_{n}\right) \beta_{n}} \\
& \times\left\langle u_{n}-P_{C}\left(u_{n}\right),-\left(P_{C}\left(u_{n}\right)-x^{*}\right)+\left(P_{C}\left(u_{n-1}\right)-x^{*}\right)\right\rangle \\
& +\frac{\alpha_{n}}{\left(1-\alpha_{n}\right) \beta_{n}}\left\langle(I-f) x_{n}-(I-f) x^{*}, x_{n}-x^{*}\right\rangle \\
& +\frac{\alpha_{n}}{\left(1-\alpha_{n}\right) \beta_{n}}\left\langle(I-f) x^{*}, x_{n}-x^{*}\right\rangle \\
& +\frac{1}{\beta_{n}}\left\langle\left(I-W_{n}\right) x_{n}-\left(I-W_{n}\right) x^{*}, x_{n}-x^{*}\right\rangle \\
& +\frac{1}{\beta_{n}}\left\langle\left(I-W_{n}\right) x^{*}, x_{n}-x^{*}\right\rangle \\
& \geq \frac{1}{\left(1-\alpha_{n}\right) \beta_{n}}\left\langle u_{n}-P_{C}\left(u_{n}\right), P_{C}\left(u_{n-1}\right)-P_{C}\left(u_{n}\right)\right\rangle \\
& +\frac{\alpha_{n}(1-\rho)}{\left(1-\alpha_{n}\right) \beta_{n}}\left\|x_{n}-x^{*}\right\|^{2} \\
& +\frac{\alpha_{n}}{\left(1-\alpha_{n}\right) \beta_{n}}\left\langle(I-f) x^{*}, x_{n}-x^{*}\right\rangle \\
& +\left\langle(I-S) x^{*}, x_{n}-x^{*}\right\rangle \text {. }
\end{aligned}
$$

Thus we have

$$
\begin{aligned}
& \left\|x_{n}-x^{*}\right\|^{2} \\
& \quad \leq \frac{\left(1-\alpha_{n}\right) \beta_{n}}{\alpha_{n}(1-\rho)}\left\langle v_{n}, x_{n}-x^{*}\right\rangle
\end{aligned}
$$

$$
\begin{aligned}
& -\frac{\left(1-\alpha_{n}\right) \beta_{n}}{\alpha_{n}(1-\rho)}\left\langle(I-S) x^{*}, x_{n}-x^{*}\right\rangle \\
& -\frac{1}{\alpha_{n}(1-\rho)}\left\langle u_{n}-P_{C}\left(u_{n}\right), P_{C}\left(u_{n-1}\right)-P_{C}\left(u_{n}\right)\right\rangle \\
& -\frac{1}{(1-\rho)}\left\langle(I-f) x^{*}, x_{n}-x^{*}\right\rangle \\
& \leq \frac{\left(1-\alpha_{n}\right) \beta_{n}}{\alpha_{n}(1-\rho)}\left\|v_{n}\right\|\left\|x_{n}-x^{*}\right\| \\
& -\frac{\left(1-\alpha_{n}\right) \beta_{n}}{\alpha_{n}(1-\rho)}\left\langle(I-S) x^{*}, x_{n}-x^{*}\right\rangle \\
& +\frac{1}{(1-\rho)}\left\|u_{n}-P_{C}\left(u_{n}\right)\right\|\left\|\frac{u_{n-1}-u_{n}}{\alpha_{n}}\right\| \\
& -\frac{1}{(1-\rho)}\left\langle(I-f) x^{*}, x_{n}-x^{*}\right\rangle \text {. }
\end{aligned}
$$

Since $\beta_{n} \leq(\tau+1) \alpha_{n}$, by (37) we have

$$
\frac{\left\|u_{n}-u_{n-1}\right\|}{\alpha_{n}} \longrightarrow 0 \quad(n \longrightarrow \infty)
$$

Combining condition (ii), $v_{n} \rightarrow 0(n \rightarrow \infty)$, (41), and (42), every weak cluster point of $\left\{x_{n}\right\}$ is also a strong cluster point. From (40), we obtain

$$
\begin{aligned}
& \left\langle(I-f) x_{n}, x_{n}-x^{*}\right\rangle \\
& =\frac{\left(1-\alpha_{n}\right) \beta_{n}}{\alpha_{n}}\left\langle v_{n}, x_{n}-x^{*}\right\rangle \\
& -\frac{1}{\alpha_{n}}\left\langle u_{n}-P_{C}\left(u_{n}\right), x_{n}-x^{*}\right\rangle \\
& -\frac{\left(1-\alpha_{n}\right)}{\alpha_{n}}\left\langle\left(I-W_{n}\right) x_{n}, x_{n}-x^{*}\right\rangle \\
& =\frac{\left(1-\alpha_{n}\right) \beta_{n}}{\alpha_{n}}\left\langle v_{n}, x_{n}-x^{*}\right\rangle \\
& -\frac{1}{\alpha_{n}}\left\langle u_{n}-P_{C}\left(u_{n}\right), P_{C}\left(u_{n}\right)-x^{*}\right\rangle \\
& -\frac{1}{\alpha_{n}}\left\langle u_{n}-P_{C}\left(u_{n}\right), P_{C}\left(u_{n-1}\right)\right. \\
& \left.-P_{C}\left(u_{n}\right)\right\rangle-\frac{\left(1-\alpha_{n}\right)}{\alpha_{n}} \\
& \times\left\langle\left(I-W_{n}\right) x_{n}-\left(I-W_{n}\right) x^{*}, x_{n}-x^{*}\right\rangle \\
& -\frac{\left(1-\alpha_{n}\right)}{\alpha_{n}}\left\langle\left(I-W_{n}\right) x^{*}, x_{n}-x^{*}\right\rangle
\end{aligned}
$$




$$
\begin{aligned}
\leq & \frac{\left(1-\alpha_{n}\right) \beta_{n}}{\alpha_{n}}\left\|v_{n}\right\|\left\|x_{n}-x^{*}\right\| \\
& +\frac{1}{\alpha_{n}}\left\|u_{n}-P_{C}\left(u_{n}\right)\right\| P_{C}\left(u_{n-1}\right)-P_{C}\left(u_{n}\right) \| \\
& -\frac{\left(1-\alpha_{n}\right) \beta_{n}}{\alpha_{n}}\left\langle(I-S) x^{*}, x_{n}-x^{*}\right\rangle \\
\leq & \frac{\left(1-\alpha_{n}\right) \beta_{n}}{\alpha_{n}}\left\|v_{n}\right\|\left\|x_{n}-x^{*}\right\| \\
& +\frac{\left\|u_{n-1}-u_{n}\right\|}{\alpha_{n}}\left\|u_{n}-P_{C}\left(u_{n}\right)\right\| \\
& -\frac{\left(1-\alpha_{n}\right) \beta_{n}}{\alpha_{n}}\left\langle(I-S) x^{*}, x_{n}-x^{*}\right\rangle .
\end{aligned}
$$

Note that the sequence $\left\{x_{n}\right\}$ is bounded; thus there exists a subsequence $\left\{x_{n_{j}}\right\}$ converging to a point $x^{\prime} \in H$. From Step 2, we have $x^{\prime} \in F(T)$. Then it follows from the above inequality, (42), and $v_{n} \rightarrow 0(n \rightarrow \infty)$ that

$$
\begin{aligned}
& \left\langle(I-f) x^{\prime}, x^{\prime}-x^{*}\right\rangle \\
& \quad \leq-\tau\left\langle(I-S) x^{*}, x^{\prime}-x^{*}\right\rangle, \quad \forall x^{*} \in F(T) .
\end{aligned}
$$

Replacing $x^{*}$ with $x^{\prime}+\mu\left(x^{*}-x^{\prime}\right)$, where $\mu \in(0,1)$ and $x^{*} \in$ $F(T)$, we have

$$
\begin{array}{r}
\left\langle(I-f) x^{\prime}, x^{\prime}-x^{*}\right\rangle \\
\leq-\tau\left\langle(I-S)\left(x^{\prime}+\mu\left(x^{*}-x^{\prime}\right)\right), x^{\prime}-x^{*}\right\rangle, \\
\forall x^{*} \in F(T) .
\end{array}
$$

Letting $\mu \rightarrow 0$, we have

$$
\begin{aligned}
& \left\langle(I-f) x^{\prime}, x^{\prime}-x^{*}\right\rangle \\
& \quad \leq-\tau\left\langle(I-S) x^{\prime}, x^{\prime}-x^{*}\right\rangle, \quad \forall x^{*} \in F(T) .
\end{aligned}
$$

If there exists another subsequence $\left\{x_{n_{j}}^{\prime}\right\}$ of $\left\{x_{n}\right\}$ converging to a point $x^{\prime \prime} \in H$. From Step 2, we also have $x^{\prime \prime} \in F(T)$. Then from (46) we obtain

$$
\left\langle(I-f) x^{\prime}, x^{\prime}-x^{\prime \prime}\right\rangle \leq-\tau\left\langle(I-S) x^{\prime}, x^{\prime}-x^{\prime \prime}\right\rangle
$$

and, via interchanging $x^{\prime}$ and $x^{\prime \prime}$,

$$
\left\langle(I-f) x^{\prime \prime}, x^{\prime \prime}-x^{\prime}\right\rangle \leq-\tau\left\langle(I-S) x^{\prime \prime}, x^{\prime \prime}-x^{\prime}\right\rangle .
$$

Adding up these two inequalities yields

$$
(1-\rho)\left\|x^{\prime}-x^{\prime \prime}\right\|^{2} \leq\left\langle(I-f) x^{\prime}-(I-f) x^{\prime \prime}, x^{\prime}-x^{\prime \prime}\right\rangle \leq 0
$$

which implies $x^{\prime}=x^{\prime \prime}$. Then $\left\{x_{n}\right\}$ converges strongly to $x^{\prime} \in F(T)$, which is the solution to the following variational inequality:

$$
\left\langle\frac{1}{\tau}(I-f) x^{\prime}+(I-S) x^{\prime}, x-x^{\prime}\right\rangle \geq 0, \quad \forall x \in F(T) .
$$

Since $I-f$ is $(1-\rho)$-strongly monotone and $I-S$ is monotone, it is easy to see that the above variational inequality has a unique solution.

Remark 15. Theorem 14 extends Theorem 3.2 in [12] from the following aspects: (i) from a nonexpansive mapping $T$ to an infinite family of nonexpansive mappings $\left\{T_{i}\right\}$; (ii) from selfmappings to nonself-mappings.

\section{Acknowledgments}

The author is extremely grateful to the referees for their useful suggestions that improved the content of the paper. Supported by the China Postdoctoral Science Foundation Funded Project (no. 2012M511928).

\section{References}

[1] W. Takahashi, Nonlinear Functional Analysis. Fixed Point Theory and Its Applications, Yokohama Publishers, Yokohama, Japan, 2000.

[2] H.-K. Xu, "Approximating curves of nonexpansive nonselfmappings in Banach spaces," Comptes Rendus de l'Académie des Sciences. Série I. Mathématique, vol. 325, no. 2, pp. 151-156, 1997.

[3] W. Takahashi and G.-E. Kim, "Strong convergence of approximants to fixed points of nonexpansive nonself-mappings in Banach spaces," Nonlinear Analysis. Theory, Methods \& Applications, vol. 32, no. 3, pp. 447-454, 1998.

[4] L. C. Ceng and A. Petruşel, "Krasnoselski-Mann iterations for hierarchical fixed point problems for a finite family of nonself mappings in Banach spaces," Journal of Optimization Theory and Applications, vol. 146, no. 3, pp. 617-639, 2010.

[5] S.-A. Zhang, X.-R. Wang, H. W. J. Lee, and C.-K. Chan, "Viscosity method for hierarchical fixed point and variational inequalities with applications," Applied Mathematics and Mechanics. English Edition, vol. 32, no. 2, pp. 241-250, 2011.

[6] D. C. Youla, "Mathematical theory of image restoration by the method of convex projections," in Image Recovery: Theory and Applications, H. Stark, Ed., pp. 29-78, Academic Press, New York, NY, USA, 1987.

[7] C. Byrne, "A unified treatment of some iterative algorithms in signal processing and image reconstruction," Inverse Problems, vol. 20, no. 1, pp. 103-120, 2004.

[8] I. Yamada, “The hybrid steepest descent method for the variational inequality problem over the intersection of fixed point sets of nonexpansive mappings," in Inherently Parallel Algorithms in Feasibility and Optimization and Their Applications (Haifa, 2000), vol. 8 of Studies in Computational Mathematics, pp. 473-504, North-Holland, Amsterdam, The Netherlands, 2001.

[9] I. Yamada, N. Ogura, and N. Shirakawa, "A numerically robust hybrid steepest descent method for the convexly constrained generalized inverse problems," in Inverse Problems, Image 
Analysis, and Medical Imaging (New Orleans, LA, 2001), vol. 313 of Contemporary Mathematics, pp. 269-305, American Mathematical Society, Providence, RI, USA, 2002.

[10] A. Moudafi, "Krasnoselski-Mann iteration for hierarchical fixed-point problems," Inverse Problems, vol. 23, no. 4, pp. 16351640, 2007.

[11] Y. Yao and Y.-C. Liou, "Weak and strong convergence of Krasnoselski-Mann iteration for hierarchical fixed point problems," Inverse Problems, vol. 24, no. 1, Article ID 015015, 8 pages, 2008.

[12] G. Marino and H.-K. Xu, "Explicit hierarchical fixed point approach to variational inequalities," Journal of Optimization Theory and Applications, vol. 149, no. 1, pp. 61-78, 2011.

[13] S.-Y. Matsushita and W. Takahashi, "Strong convergence theorems for nonexpansive nonself-mappings without boundary conditions," Nonlinear Analysis. Theory, Methods \& Applications, vol. 68, no. 2, pp. 412-419, 2008.

[14] P. L. Combettes, "Quasi-Fejérian analysis of some optimization algorithms," in Inherently Parallel Algorithms in Feasibility and Optimization and Their Applications (Haifa, 2000), D. Butnariu, Y. Censor, and S. Reich, Eds., vol. 8 of Studies in Computational Mathematics, pp. 115-152, North-Holland, Amsterdam, The Netherlands, 2001.

[15] H.-K. Xu, "Iterative algorithms for nonlinear operators," Journal of the London Mathematical Society. Second Series, vol. 66, no. 1, pp. 240-256, 2002.

[16] J.-P. Gossez and E. Lami Dozo, "Some geometric properties related to the fixed point theory for nonexpansive mappings," Pacific Journal of Mathematics, vol. 40, no. 3, pp. 565-573, 1972.

[17] J. S. Jung, "Iterative approaches to common fixed points of nonexpansive mappings in Banach spaces," Journal of Mathematical Analysis and Applications, vol. 302, no. 2, pp. 509-520, 2005.

[18] Y. Song and R. Chen, "Viscosity approximation methods for nonexpansive nonself-mappings," Journal of Mathematical Analysis and Applications, vol. 321, no. 1, pp. 316-326, 2006.

[19] J. G. O’Hara, P. Pillay, and H.-K. Xu, “Iterative approaches to convex feasibility problems in Banach spaces," Nonlinear Analysis. Theory, Methods \& Applications, vol. 64, no. 9, pp. 2022-2042, 2006. 


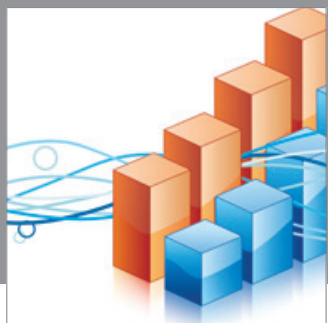

Advances in

Operations Research

mansans

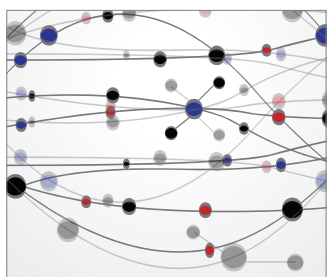

The Scientific World Journal
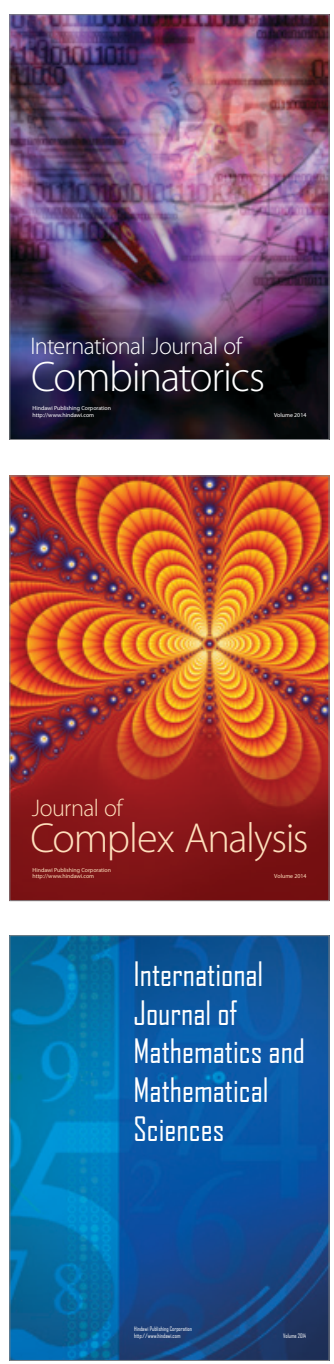
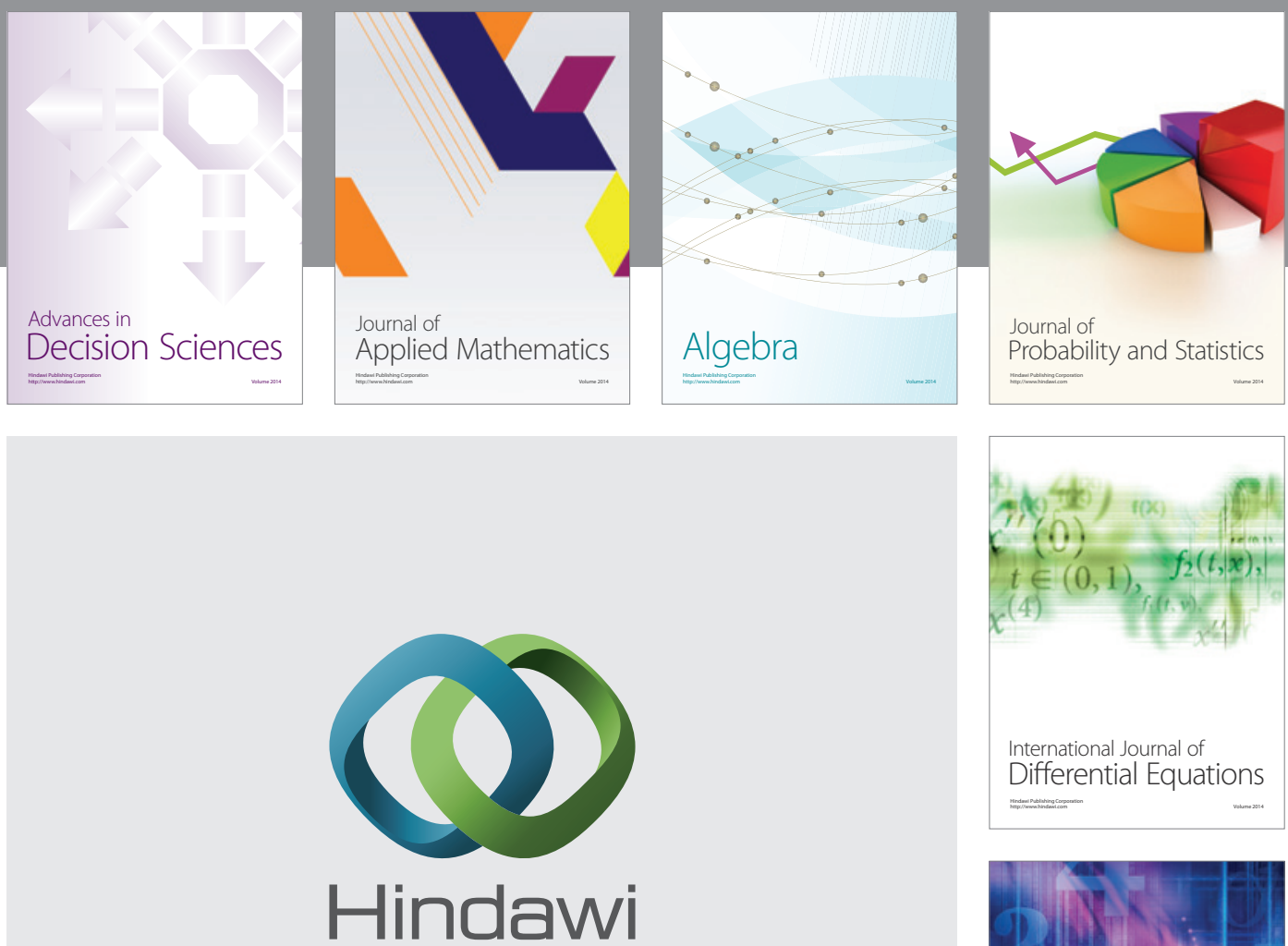

Submit your manuscripts at http://www.hindawi.com
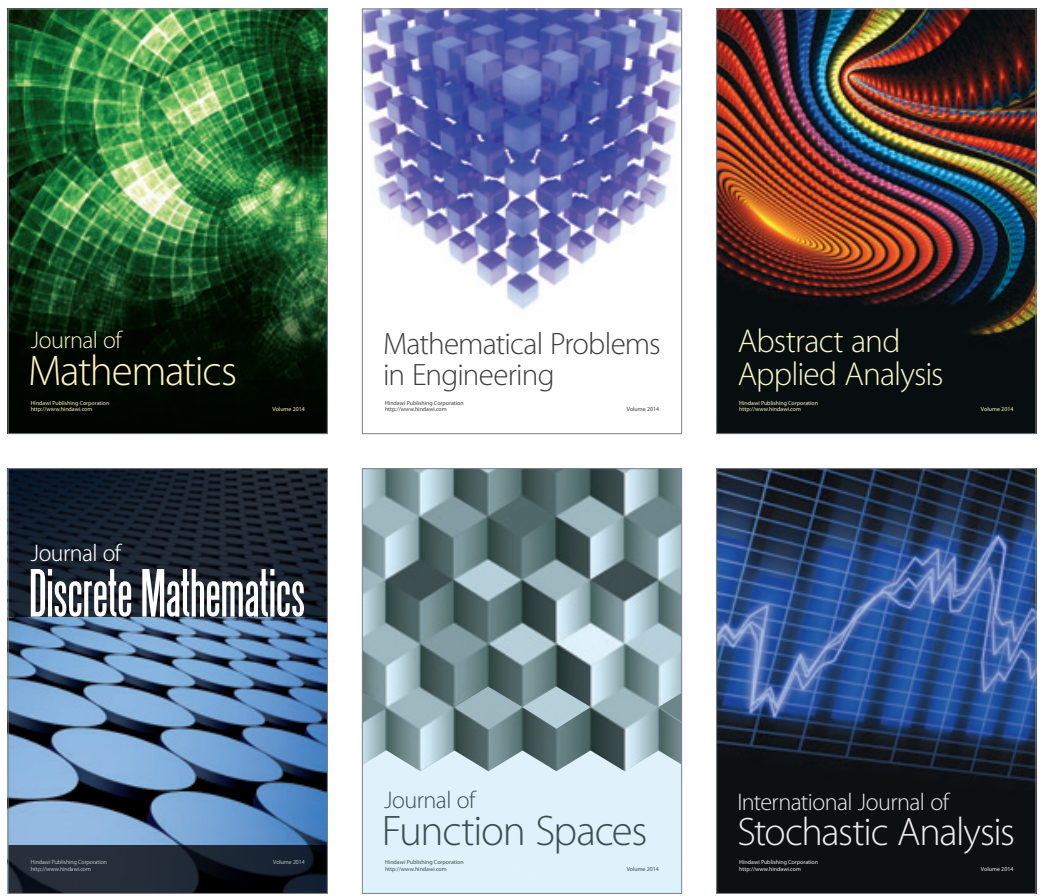

Journal of

Function Spaces

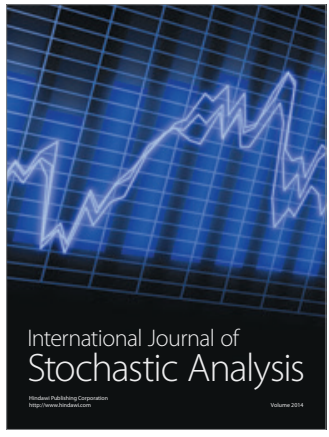

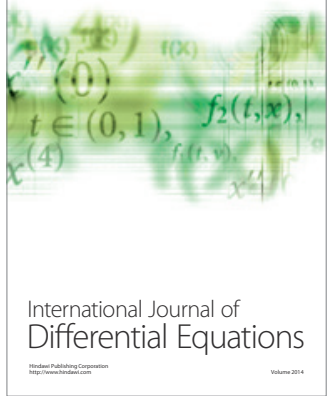
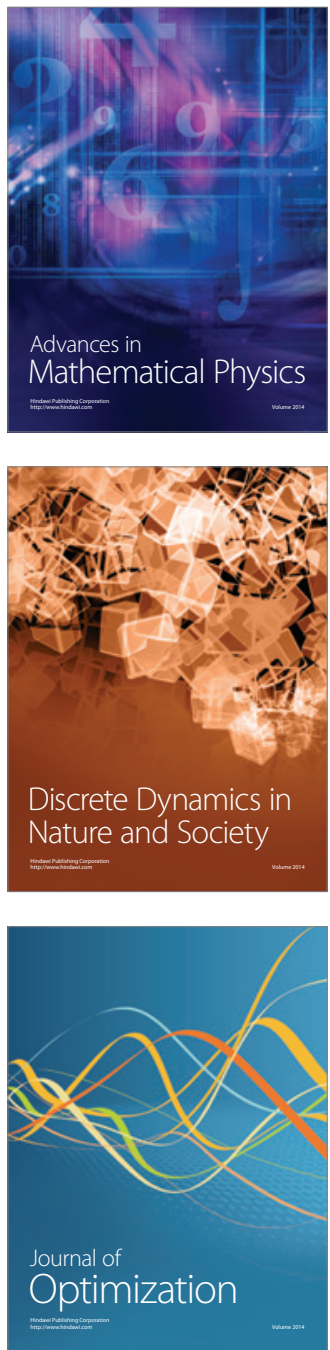